\title{
PENGARUH ATHLETIC BASIC COORDINATION TERHADAP KEMAMPUAN LARI 60 METER
}

\section{THE EFFECT OF ATHLETIC BASIC COORDINATION ON 60 METER RUNNING ABILITY}

\author{
Andika Triansyah \\ Program Studi Pendidikan Jasmani Universitas Tanjungpura, Pontianak, Indonesia \\ *Corresponding Author: Andika Triansyah, andika.triansyah@fkip.untan.ac.id
}

Received: 2021-03-17; Revised: 2021-03-26; Accepted: 2021-04-05

\begin{abstract}
Abstrak
Permasalahan utama dalam penelitian ini adalah belum optimalnya kemampuan lari 60 meter mahasiswa prodi Pendidikan Jasmani Fakultas Keguruan dan Ilmu Pendidikan Universitas Tanjungpura diduga karena pengaruh teknik berlari yang tidak tepat serta kemampuan fisik yang kurang mendukung. Tujuan penelitian ini untuk meningkatkan kemampuan lari 60 meter dengan latihan athletic basic coordination. Penelitian ini menggunakan metode eksperimen dengan desain praeksperimental. Adapun sampel penelitian menggunakan mahasiswa program studi Pendidikan Jasmani Universitas Tanjungpura. Teknik pengampilan sampel digunakan purposive sampling dengan kreteria sampel memiliki teknik dasar lari 60 meter dan kemampuan power otot tungkai yang rendah, sehingga didapat 20 sampel penelitian yang relevan. Analisis data menggunakan uji-t (uji hipotesis) dengan prasyarat uji normalitas dan uji homogenitas. Berdasarkan hasil analisis data menunjukkan bahwa $\mathrm{t}$ hitung lebih besar dari pada $\mathrm{t}_{\text {tabel }}$ atau 11,18>2,16 yang berarti terdapat pengaruh latihan athletic basic coordination terhadap kemampuan lari 60 meter pada mahasiswa program studi Pendidikan Jasmani Universitas Tanjungpura.
\end{abstract}

Kata Kunci: athletic basic coordination, kemampuan lari, 60 meter

\begin{abstract}
The main problem in this research is the 60-meter running ability of students of the Physical Education Study Program, Faculty of Teacher Training and Education, Tanjungpura University, which is thought to be caused by the influence of inappropriate and less supportive running techniques. physical abilities. The purpose of this study was to improve the ability to run 60 meters with basic athletic coordination training. This research uses an experimental method with a pre-experimental design. The research sample used the Physical Education student study program at the University of Tanjungpura. The sampling technique used was purposive sampling with the sample criteria having the basic technique of running 60 meters and low leg muscle strength, to obtain 20 relevant research samples. Data analysis used a t-test (hypothesis test) with the prerequisite for normality test and homogeneity test. Based on the results of data analysis, it shows that it is greater than $t_{\text {table }}$ or $11.18>2.16$, which means that there is an effect of basic coordination of athletic training on the ability to run 60 meters in Physical Education study program students. , Tanjungpura University.
\end{abstract}

Keywords: athletic basic coordination, running ability, 60 meters

How To Cite: Triansyah, Andika. (2021). Pengaruh athletic basic coordination terhadap kemampuan lari 60 meter. Journal of Sport Education (JOPE), 3 (2), 75-84. doi: http://dx.doi.org/10.31258/jope.3.2.75-84

Journal of Sport Education (JOPE) is an open access article under the CC-BY-SA 4.0 License

\section{PENDAHULUAN}

Salah satu cabang olahraga individu yang populer adalah atletik, tidak hanya sebatas sebagai olahraga prestasi, atletik juga masuk dalam kurikulum pendidikan di Indonesia 
sebagai upaya memperbaiki kualitas gerak dasar dari peserta didik. Atletik sebagai cabang olahraga tertua didunia sudah sepantasnya menjadi ibu dari setiap cabang olahraga (Triansyah, 2020). Implementasi dari cabang olahraga atletik yang terdiri dari banyak gerakan seperti gerakan berjalan, berlari, melompat dan melempar merupakan kunci dasar pengalaman gerak yang harus dimiliki pada anak-anak ataupun remaja secara komprehensif (Sidik, 2017). Pengalaman gerak tersebut jika dilatih dengan tepat dan berkelanjutan tentu akan memberikan kontribusi bagi kemampuan gerak dasar yang baik dan diperlukan pada setiap cabang olahraga. Sebagai contoh kemampuan berlari yang baik tentu harus dimiliki setiap anak terlebih lagi bagi seorang atlet. Lari yang secara terminologi adalah memaksimalkan frekuensi langkah dipercepat sehingga pada aktivitas tersebut terdapat kecenderungan posisi badan melayang atau pada saat berlari paling tidak hanya satu kaki yang menyentuh permukaan tanah (Purnomo \& Dapan, 2011). Hampir disetiap cabang olahraga yang predominan menggunakan sistem energi anaerobik memerlukan kualitas lari yang baik atau lebih dalam memerlukan kelincahan yang baik, yang artinya lari diperlukan sebagai dasar bagi kondisi fisik atlet untuk mencapai performa terbaik dalam berolahraga.

Aktivitas berlari sangat erat dengan efek anaerobik dan aerobik yang tinggi, mampu memperkuat pembuluh/otot jantung sehingga memperlancar jalannya darah keseluruh tubuh, selain itu daya tahan tubuh juga akan meningkat, serta lemak dan kolesterol menjadi berkurang (Suharjana, 2013). Dalam olahraga prestasi lari identik dengan kecepatan yang sangat diperlukan untuk mempersiapkan kondisi umum tubuh atau general anatomical pada bagian kecepatan sehingga lebih lanjut dapat dijadikan dasar untuk melatih kelincahan atlet dan mendorong ambang rangsang laktat sehingga atlet tidak mudah mengalami kelelahan karena kelelahan yang cepat terjadi akan berdampak buruk pada penampilan atlet pada cabang olahraga apapun. Seperti penelitian yang dihasilkan oleh (Rusdiana, 2020), bahwa kelelahan yang terjadi dalam permainan bulu tangkis berpengaruh pada perubahan kinematika gerak pada saat overhead jumping smash. Artinya kelelahan fisik yang terjadi dapat mengakibatkan menurunnya peforma atlet, sehingga disarankan untuk melalukan latihan yang dapat meningkatkan power atlet itu sendiri yang tentunya dapat mendorong ambang rangsang laktat agar tidak mudah lelah. Lari juga berkontribusi untuk meningkatkan kondisi aerobik atlet, terutama jika lari yang dilakukan dengan durasi yang lama sehingga aktivitas tersebut akan meningkatkan daya tahan jantung dan otot atlet yang akan berpengaruh langsung pada sistem energi aerobik. Dari penjelasan di atas dapat disimpulkan bahwa pentingnya meningkatkan kemampuan lari sebagai upaya untuk mendorong atau meningkatkan kemampuan fisik yang diperlukan dalam mencapai performa terbaik pada saat berolahraga.

Kemampuan seseorang dalam berlari dapat didukung oleh beberapa faktor diantaranya kapasitas fisik seperti kekuatan otot dan daya tahan vascular. Kecepatan dan akselerasi adalah komponen penting dari sebagian besar olahraga, ada berbagai cara untuk melatihnya, diantaranya latihan beban atau dikenal dengan istilah metode resisted dan assisted digunakan dalam program pelatihan untuk meningkatkan kinerja (Leyva, Wong, \& Brown, 2017). Selain itu faktor teknik dasar juga memberikan kontribusi terhadap kemampuan berlari, melatih teknik dasar berlari dapat dilakukan dengan latihan yang berulang dengan jarak 40 meter (Tønnessen, Shalfawi, Haugen, \& Enoksen, 2011). Latihan untuk memperbaiki teknik lari jarak pendek sekaligus meningkatkan kapasitas fisik dapat dilakukan dengan metode latihan 
athletic basic coordination atau lebih dikenal dengan abc running drill. Istilah abc running drill sebenarnya lebih diutamakan pada gerak lari yang bervariasi dan disusun berdasarkan sistematika berbagai bentuk gerakan kaki dari yang mudah ke yang sukar (Brown \& Ferrigno, 2014). Oleh sebab itu proses latihan perlu direncanankan secara optimal agar dapat memenuhi tujuan dan harapan yang akan dicapai dalam hasil yang baik.

Pengembangan kekuatan otot dan kompetensi keterampilan motorik yang sinergis merupakan pusat pengembangan atletik jangka panjang (Radnor et al., 2020). Latihan lari jarak pendek dengan abc running drill merupakan latihan teknik dasar untuk memperkuat kekuatan otot dan memperbaiki gerak dasar, kekuatan otot dan teknik dasar berlari akan berpengaruh terhadap hasil lari 60 meter (Henriksen, Stambulova, \& Roessler, 2010). Sehingga penting sekali memperhatikan kedua hal tersebut untuk meningkatkan penampilan dalam berlari. Kecepatan adalah keterampilan yang ditentukan oleh jenis serat otot dan karakteristik bawaan selain itu faktor pelatihan berkontribusi sebagian untuk perbaikannya. Koordinasi antara efektivitas aktif intramuskuler dan intermuskuler pada gerak sangat penting dalam perkembangan linier kecepatan (Bilge, Caglar, \& Saavedra, 2020). Dengan demikian dapat disimpulkan untuk memperbaiki kecepatan maka diperlukan latihan koordinasi yang tepat sehingga mampu melibatkan kondisi fisiologis tubuh dengan mekanika gerak yang tepat sehingga memberikan kontribusi pada kecepatan berlari.

Latihan abc running drill yang dilakukan dengan perencanaan terukur akan memberikan dampak perubahan yang signifikan dikarenakan latihan tersebut selain melatih koordinasi gerak juga berdampak pada peningkatan kapasitas fisik yang akan mendukung performa dalam berlari, seperti meningkatkan power otot tungkai, daya tahan otot dan kekuatan otot. Penelitian yang relevan dilakukan (Sobarna, Hambali, Sutiswo, \& Sunarsi, 2020) bahwa latihan dengan $a b c$ running mempunyai pengaruh yang signifikan dibandingkan dengan latihan tanpa abc running terhadap kemampuan sprint peserta didik SMA 3 Subang. Penelitian lainnya (Setyantoko, Widiastuti, \& Hernawan, 2019) menghasilkan bahwa model latihan lari abc berbasis permainan cukup efektif untuk meningkatkan kecepatan lari 30 meter pada usia atlet 6 - 12 tahun. Dalam penelitian ini yang dilakukan selain memberikan latihan dengan $a b c$ running drill terdapat tambahan adanya intervensi gerak melalui pemberian stimulus visualisasi rekaman video $a b c$ running drill dan gerakan lari yang seharusnya dilakukan. Sehingga dengan tambahan pemberian video dapat mempercepat perbaikan kualitas teknik dasar dalam berlari.

Penelitian dilakukan dengan mempertimbangkan subjek penelitian yang memiliki kualitas teknik dasar berlari yang rendah dan kondisi fisik yang lemah, sehingga hasil penelitian dapat memberikan kontribusi terhadap perbaikan kualitas teknik dasar yang baik. Perbaikan tersebut terjadi melalui peningkatan koordinasi gerak sehingga teknik lari yang dilakukan lebih efisien dan efektif. Selain itu juga kontribusi terhadap kondisi fisik, seperti meningkatkan power otot tungkai dan daya tahan otot dengan pengulangan latihan yang dilakukan sehingga mampu menambah kemampuan dalam lari 60 meter. Pentingnya gerakan yang benar dalam lari jarak pendek (sprint) menjadikan gerakan lari lebih efisien dan dapat mengurangi tenaga yang terbuang sia-sia pada saat berlari akibat teknik berlari yang salah (Brown \& Ferrigno, 2014). Dari uraian tersebut penelitian ini bertujuan untuk meningkatkan kemampuan lari 60 meter dengan cara memberikan latihan abc running drill yang dikombinasikan dengan latihan visualiasi. 


\section{METODE}

Metode yang digunakan dalam penelitian ini adalah eksperimen. Secara umum metode penelitian eksperimen diartikan sebagai penelitian yang melihat dan meneliti adanya akibat setelah subyek diberikan perlakuan pada variabel bebas. Desain penelitian yang digunakan adalah Pre-Experimental Design dengan rancangan yaitu One Group Pretest-Posttest. Lebih jelas dapat dilihat pada tabel 1. Populasi dan sampel peneliti adalah mahasiswa prodi Pendidikan Jasmani FKIP Universitas Tanjungpura, teknik pengambilan sampel dengan purposive sampling atau teknik pengambilan sampel dengan menentukan kriteria tertentu (Sugiyono, 2014). Adapun kriteria yang ditetapkan adalah dengan memperhatikan teknik dasar lari 60 meter dan kemampuan power otot tungkai yang rendah, sehingga didapat jumlah sampel sebanyak 20 mahasiswa. Subjek selanjutnya akan diberikan program latihan yang terukur dan terencana dengan bentuk latihan abc running drill yang dikombinasi dengan latihan visualisasi. Bentuk latihan abc running drill dalam penelitian ini adalah angkling, skipping, high-knee, shape of high-knees skipps, straight-leg shuffle, butt-kickers, cross step-over running. Latihan visualisasi diberikan sebagai supplement latihan yang di berikan diawal sesi latihan, dengan cara menayangkan video teknik berlari yang benar pada penelitian ini digunakan video sprint Usain Bolt dan Lalu Muhammad Zohri.

Tabel 1. Desain One Group Pretest-Posttest

\begin{tabular}{lll}
\hline Pretest & Perlakuan & Posttest \\
\hline $\mathrm{O}_{1}$ & $\mathrm{X}$ & $\mathrm{O}_{2}$ \\
\hline
\end{tabular}

Sumber: (Sugiyono, 2014)

Teknik pengumpulan data digunakan tes dan pengukuran dengan instrument tes lari 60 meter. Selanjutnya analisis data menggunakan uji parametrik rumus t-tes dengan prasyarat uji normalitas dan uji homogenitas.

\section{HASIL}

\section{Uji Normalitas}

Uji prasyarat analisis data digunakan uji normalitas dengan menggunakan rumus perhitungan chi kuadrat $\left(x^{2}\right)$ data yang digunakan adalah data pretest dan posttest dengan hasil menunjukan data pretest $\mathrm{x}^{2}$ hitung $=2,46$ dan data posttest dengan hasil perhitungan $\mathrm{x}^{2}$ tabel $=$ 2,80. Adapun data hasil perhitungan selengkapnya ada pada tabel 2 berikut:

Tabel 2. Deskripsi Data Uji Normalitas

\begin{tabular}{llllll}
\hline Tes & Sampel & Rata- rata & $\mathrm{x}^{2}$ hitung & $\mathrm{x}^{2}$ tabel & Keterangan \\
\hline Pretest & 20 & 5,55 & 2,46 & 5,991 & Normal \\
Postest & 20 & 12,65 & 2,80 & 5,991 & Normal \\
\hline
\end{tabular}

Kriteria pengujian jika nilai $\mathrm{x}^{2}$ hitung $<\mathrm{x}^{2}$ tabel maka data berdistribusi normal. Dalam perhitungan ditemukan data pretest $\mathrm{x}^{2}$ hitung $=2,46$, selanjutnya dibandingkan dengan $\mathrm{x}^{2}$ tabel $=$ 5,991 , jadi dapat dikatakan data pretest $\mathrm{x}^{2}$ hitung $<\mathrm{x}^{2}$ tabel, maka dapat disimpulkan bahwa data prestest berdistribusi normal. Selanjutnya dilakukan perhitungan pada data posttest dengan hasil perhitungan $\mathrm{x}^{2}$ tabel $=2,80$ dan $\mathrm{x}^{2}$ tabel $=5,991$. Jadi dapat dikatakan data posttest $\mathrm{x}^{2}$ hitung $<$ 
$\mathrm{x}^{2}$ tabel, maka dapat disimpulkan data posttest berdistribusi normal. Dengan demikian untuk perhitungan uji normalitas data pretest dan posttest disimpulkan berdistribusi normal.

\section{Uji Homogenitas}

Uji prasyarat selanjutnya adalah uji homogenitas untuk memastikan bahwa populasi/sampel yang diukur homogen pada penelitian ini digunakan adalah uji Fisher (uji F) dengan hasil $F_{\text {hitung }}=1,02$. Adapun data selengkapnya pada tabel 3, sebagai berikut:

Tabel 3. Deskripsi Data Uji Homogenitas

\begin{tabular}{llllll}
\hline Tes & Jumlah Sampel & Varians & $F_{\text {hitung }}$ & $F_{\text {tabel }}$ & Keterangan \\
\hline Pretest & 20 & 7,2 & 1,02 & 2,16 & Homogen \\
Postest & 20 & 7,36 & & & \\
\hline
\end{tabular}

Kriteria pengujian, data dikatakan homogen jika nilai $F_{\text {hitung }}<F_{\text {tabel }}$. Selanjutnya dilihat dari data yang diperoleh di atas nilai $F_{\text {hitung }}$ sebesar 1,02 lebih kecil jika dibandingkan dengan $F_{\text {table }}$ sebesar 2,16 atau $F_{\text {hitung }}(1,02)<F_{\text {tabel }}(2,16)$ dengan demikian dapat disimpulkan bahwa data Homogen.

\section{Uji Pengaruh}

Setelah data dipastikan berdistribusi normal dan homogen maka perhitungan dilanjutkan dengan melakukan uji pengaruh parametrik dengan uji signifikansi taraf 5\%. Adapun kriteria perhitungan jika $t_{\text {hitung }}>t_{\text {tabel }}$ maka terdapat pengaruh yang signifikan dari variable yang diukur. Adapun perhitungan yang digunakan telah mengubah data kecepatan lari dengan penilaian berdasarkan rumus $t_{\text {score, }}$ untuk data selengkapnya dapat dilihat pada tabel 4 berikut:

Tabel 4. Data Uji Pengaruh

\begin{tabular}{llllll}
\hline Tes & Mean $\mathrm{t}_{\text {score }}$ & $\mathrm{t}_{\text {hitung }}$ & $\mathrm{dk}$ & $\mathrm{t}_{\text {tabel }}$ & Keterangan \\
\hline Pretest & 14,78 & 11,18 & 19 & 2,16 & Terdapat pengaruh \\
Postest & 19 & & & & \\
\hline
\end{tabular}

Dilihat dari tabel 4 , nilai $t_{\text {hitung }}>\mathrm{t}_{\text {tabel }}$ atau 11,18 $>2,16$. Berdasarkan kriteria penarikan kesimpulan maka dapat dikatakan bahwa terdapat pengaruh yang signifikan abc running drill terhadap kemampuan lari 60 meter pada mahasiswa prodi Pendidikan Jasmani FKIP Untan. Adapun pengaruh yang dihasilkan sebesar 22\%. Lebih lanjut ditampilkan pada gambar 1 diagram rata-rata perhitungan kecepatan kemampuan lari 60 meter setelah dikonversi menggunakan $\mathrm{t}_{\text {score }}$

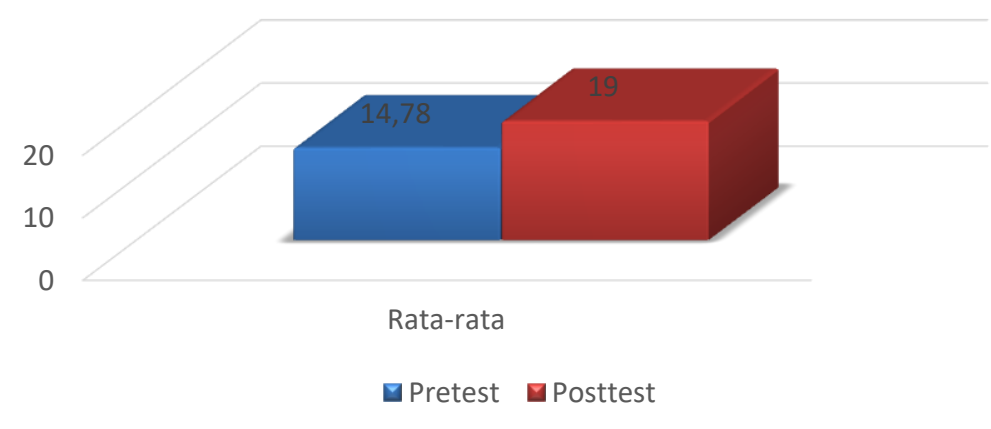

Gambar 1. Diagram rata-rata kemampuan lari 60 meter ( $t$ score) 


\section{PEMBAHASAN}

Kecepatan merupakan komponen fisik yang diperlukan hampir pada setiap cabang olahraga, terlebih olahraga yang memiliki karakteritik intensitas tinggi. Oleh karena itu kecepatan merupakan komponen fisik yang harus dilatihkan agar mendukung penampilan pada olahraga tersebut. Melatih kecepatan (speed) umumnya dilakukan setelah atlet dilatih daya tahan (endurance) dan kekuatannya (strength). Dengan dasar kekuatan dan daya tahan yang dimiliki atlet atau atlet memiliki kapasitas aerobik yang baik maka melatih kecepatan akan lebih mudah untuk dilakukan, latihan dengan meningkatkan ambang rangsang anaerobik sehingga atlet tidak mudah mengalami kelelahan atau dengan kata lain pada saat berlari fase kecepatan maksimal akan lama durasinya sebelum atlet mengalami kelelahan (Sukadiyanto \& Muluk, 2011; Triansyah \& Haetami, 2020). Bentuk latihan yang dapat digunakan untuk mencapai tujuan tersebut adalah abc running drill yang dapat meningkatkan kondisi fisik (kebugaran), kemampuan koordinasi dan mobilitas yang diartikulasikan secara bersama dengan melakukan gerakan berulang-ulang (Čillík \& Willwéber, 2018). Sehingga dapat dikatakan latihan dengan metode abc running drill relevan untuk diterapkan sebagai upaya meningkatkan kecepatan/kemampuan lari.

Peak performance (penampilan terbaik) berhubungan dengan kondisi fisik dan teknik/gerak dasar yang baik. Gerakan yang dilakukan dengan efisiensi dapat berdampak pada pengeluaran energi yang tepat dan membuat tubuh tidak mudah lelah, sehingga berdampak pada performa atlet (Brewer, 2017). Latihan yang dilakukan secara teratur dan terukur merupakan kunci utama untuk meningkatkan penampilan dalam olahraga. Latihan membangun kondisi fisik secara umum dan spesifik sehingga modal awal sebagai atlet sudah dimiliki, selanjutnya latihan juga membentuk psikis olahragawan agar terbangun mental tanding yang diharapkan dan latihan juga mengembangkan dan menyempurnakan strategi dan taktik bertanding yang diperlukan untuk penampilan terbaik pada saat kompetisi. Untuk meningkatkan kondisi fisik terutama komponen kecepatan perlu diperhatikan keterlatihan dan usia latihan, dan faktor lain yang perlu menjadi perhatian juga adalah karakteristik bawaan/jenis serabut otot yang dimiliki atlet, untuk jenis otot serabut putih berkontribusi pada kecepatan (Freeman, 2015).

Latihan yang memiliki karakteristik high impact akan berkontribusi langsung pada kinerja kecepatan, namun perlu juga diperhatikan lamanya latihan atau sesi latihan. Seperti penelitian yang dilakukan (Beato, Bianchi, Coratella, Merlini, \& Drust, 2018), melalui latihan plyometric selama sesi latihan yang dilakukan kurang dari 8 minggu mampu memberikan beberapa peningkatan yang berarti dalam parameter lompat dan kecepatan pada pemain sepak bola elit namun perubahan yang terjadi tergolong kecil. Selain itu ladder drill dan $S A Q$ yang dilakukan selama 8 minggu dengan 3 sesi setiap minggunya terbukti mampu meningkatkan kecepatan dan kelincahan pemain bulu tangkis (Chandrakumar \& Ramesh, 2015). Dari hasil penelitian di atas dapat disimpulkan bahwa latihan fisik yang berhubungan dengan power, agility, strength jika dilatih dengan waktu yang cukup minimal 8 minggu terbukti dapat meningkatkan kecepatan.

Latihan pendukung lainya yang dapat meningkatkan kemampuan atlit adalah dengan teknik visualisasi. Visualisasi merupakan teknik yang dapat digunakan untuk membantu atlet mengatasi kecemasan dalam berolahraga dan sangat erat hubungannya dengan latihan mental untuk meningkatkan performa serta kemampuan gerak olahraga (Newmark, 2012). 
Dibeberapa penelitian teleh terbukti pelatihan mental atau mindful sport performance enhancement (MSPE) training dapat meingkatkan performa olahraga. Penelitian (Glass, Spears, Perskaudas, \& Kaufman, 2019; Mistretta et al., 2017), menghasilkan bahwa MSPE pada atlet perguruan tinggi olahraga melaporkan mendapatkan manfaat psikologis baik dalam olahraga maupun kehidupan sehari-hari seperti releksasi, kecemasan, mental toughness, and self-awareness secara keseluruhan menyampaikan pengalaman positif dan melaporkan manfaat yang sama terhadap kinerja olahraga. Salah satu bentuk latihan psikologi adalah dengan visualisasi atau imagery training, dengan mengamati video sebelum latihan inti diharapkan dapat memberikan sumbangan terhadap kemampuan berlari. Latihan abc running drill dengan mengkombinasikan visualisasi akan memaksimalkan potensi bawaan yang ada dengan kemampuan fisik, teknik dan mental atlet. Beberapa penelitian yang relevan seperti (Akbar, Priambodo, \& Jannah, 2019) terdapat pengaruh yang signifikan latihan imagery dan tingkat konsentrasi terhadap peningkatan keterampilan lay up shoot bola basket pada peserta didik SMAN 1 Menganti Gresik. Selanjutnya penelitian (Susiono \& Hernawan, 2020) metode unifikasi yang memperkenalkan gerak dasar running abc yang baik, efisien dan hormonis sehingga mampu mendiskripsikan kesalahan gerak dasar yang sering dilakukan mahasiswa saat latihan. Penelitian (Wulandari \& Jannah, 2018), hasil penelitian yang dilakukan menunjukkan ada pengaruh PETTLEP Imagery terhadap efikasi diri atlet lari 100 meter perorangan, atlet menyadari pentingnya aspek psikologis dalam meningkatkan performa latihan dan menghadapi perlombaan selain itu perasaan siap menghadapi proses latihan dan merasa lebih yakin dengan kemampuan untuk bisa menjalani latihan berat.

Latihan abc running drill yang dilakukan pada penelitian ini bervariasi dengan bentuk gerakan angkling, skipping, high-knee, shape of high-knees skipps, straight-leg shuffle, buttkickers, cross step-over running. Latihan dilakukan selama 8 minggu dengan 3 sesi latihan seminggu dan waktu latihan inti selama 60 menit. Di setiap sesi latihan selalu diawali dengan latihan visualisasi/imagery untuk mempersiapkan diri dan memberikan gambaran terhadap teknik gerakan yang harus dipelajari. Pengulangan-pengulangan yang dilakukan selama latihan membentuk koordinasi gerak dasar kecepatan sehingga teknik berlari menjadi lebih baik. Pengulangan yang dilakukan dengan memperhatikan intensitas dan volume latihan yang tepat (prinsip latihan overload) memberikan kontribusi terhadap meningkatknya kondisi fisik, selain itu upaya memperbaiki teknik dasar dengan menanamkan pemahaman teknik dasar berlari yang benar melalui visualisasi atau memutarkan video sebelum latihan inti dimulai dengan harapan terbentuknya citra (imagery) terhadap gerakan yang seharusnya dilakukan. Hasil penelitian ini juga didukung oleh penelitian yang telah dilakukan (Robin et al., 2011) tentang dampak dari motor imagery mampu meningkatkan kemampuan akurasi pengembalian servis pemain tenis lapangan, setelah latihan selama 48 jam jika dibandingkan dengan pemain yang tidak mendapat perlakuan motor imagery. Pencitraan terhadap gerak yang benar dan dilakukan berulang-ulang akan memberikan rekaman memori di otak bawah sadar atau terciptanya gerakan otomatisasi. Sehingga dari hasil penelitian ini dapat disampaikan bahwa latihan abc running drill dengan pendekatan visualisasi berpengaruh terhadap kemampuan lari 60 meter. Hal tersebut dapat dilihat rata-rata kemampuan lari setelah dilakukan perhitungan dengan $t$-score yang menunjukan pada data pretest skor 14,78 dan data posttest skor 19 atau memberikan pengaruh sebesar $22 \%$. 


\section{SIMPULAN}

Dari hasil penelitian ini dapat disimpulkan bahwa terdapat pengaruh athletic basic coordination (abc running drill) terhadap kemampuan lari 60 meter pada mahasiswa prodi Pendidikan Jasmani. Adapun pengaruh tersebut disebabkan oleh perbaikan teknik dasar lari 60 meter mahasiswa, meningkatnya kemampuan fisik mahasiswa dan citra diri. Temuan penelitian menghasilkan abc running drill memperbaiki koordinasi antara efektivitas aktif intramuskuler dan intermuskuler pada gerak dasar yang penting dalam peningkatan kecepatan lari 60 meter, sementara teknik visualisasi mengintervensi citra positif terhadap kemampuan diri yang dimiliki sehingga kemampuan berlari 60 meter mahasiswa mengalami peningkatan.

\section{DAFTAR PUSTAKA}

Akbar, M. F., Priambodo, A., \& Jannah, M. (2019). Pengaruh Latihan Imagery dan Tingkat Konsentrasi Terhadap Peningkatan Keterampilan Lay Up Shoot Bola Basket SMAN 1 Meganti Gresik. Jp.Jok (Jurnal Pendidikan Jasmani, Olahraga Dan Kesehatan), 2(2), 1-13. Retrieved from https://doi.org/10.33503/jpjok.v2i2.445

Beato, M., Bianchi, M., Coratella, G., Merlini, M., \& Drust, B. (2018). Effects of Plyometric and Directional Training on Speed and Jump Performance in Elite Youth Soccer Players. Journal of Strength and Conditioning Research, 32(2), 289-296. Retrieved from https://doi.org/10.1519/JSC.0000000000002371

Bilge, M., Caglar, E., \& Saavedra, J. M. (2020). The roles of some agility performance parameters on the linear, single sprint skills of young male basketball and handball players. Progress in Nutrition, 22(May), 72-79. Retrieved from https://doi.org/10.23751/pn.v22i1-S.9788

Brewer, C. (2017). Athletic Movement Skills: training for sports performance. Champaign: Human Kinetics.

Brown, L. E., \& Ferrigno, V. A. (2014). Training for Speed, Agility, and Quickness (Thrid edit). Champaign: Human Kinetics.

Chandrakumar, N., \& Ramesh, C. (2015). Effect of ladder drill and SAQ training on speed and agility among sports club badminton players. International Journal of Applied Research, 1(12), 527-529. Retrieved from https://mkuniversity.ac.in/new/school/sedu/journal/Physical_Education/Dr.C.Ramesh/ 1.Effect_of_ladder_drill_and_SAQ_training_on_speed_and_Agility_among_sports_club_bad minton_players.pdf

Čillík, I., \& Willwéber, T. (2018). Influence of an exercise programme on level of coordination in children aged 6 to 7. Journal of Human Sport and Exercise, 13(2). Retrieved from https://doi.org/10.14198/jhse.2018.132.14

Freeman, W. (2015). Track \& Field Coaching Essentials. New York: USATF Properties.

Glass, C. R., Spears, C. A., Perskaudas, R., \& Kaufman, K. A. (2019). Mindful Sport Performance Enhancement: Randomized Controlled Trial of a Mental Training Program With Collegiate Athletes. Journal of Clinical Sport Psychology, 13(4), 609-628. Retrieved from https://doi.org/10.1123/jcsp.2017-0044 
Henriksen, K., Stambulova, N., \& Roessler, K. K. (2010). Successful talent development in track and field: Considering the role of environment. Scandinavian Journal of Medicine and Science in Sports, 20(SUPPL. 2), 122-132. Retrieved from https://doi.org/10.1111/j.1600-0838.2010.01187.x

Leyva, W. D., Wong, M. A., \& Brown, L. E. (2017). Resisted and Assisted Training for Sprint Speed: A Brief Review. Journal of Physical Fitness, Medicine and Treatment in Sports, 1(1), 555554.

Retrieved from https://juniperpublishers.com/jpfmts/pdf/JPFMTS.MS.ID.555554.pdf

Mistretta, E. G., Glass, C. R., Spears, C. A., Perskaudas, R., Kaufman, K. A., \& Hoyer, D. (2017). Collegiate Athletes' Expectations and Experiences With Mindful Sport Performance Enhancement. Journal of Clinical Sport Psychology, 11(3), 201-221. Retrieved from https://doi.org/10.1123/jcsp.2016-0043

Newmark, T. (2012). Cases in Visualization for Improved Athletic Performance. Psychiatric Annals, 42(10), 385-387. Retrieved from https://doi.org/10.3928/00485713-2012100307

Purnomo, E., \& Dapan. (2011). Dasar - Dasar Gerak Atletik (1st ed.). Yogyakarta: Alfamedia.

Radnor, J. M., Moeskops, S., Morris, S. J., Mathews, T. A., Kumar, N. T. A., Pullen, B. J., ... Lloyd, R. S. (2020). Developing Athletic Motor Skill Competencies in Youth. Strength \& Conditioning Journal, 42(6), 54-70. Retrieved from https://doi.org/10.1519/SSC.0000000000000602

Robin, N., Dominique, L., Toussaint, L., Blandin, Y., Guillot, A., \& Her, M. Le. (2011). Effects of motor imagery training on service return accuracy in tennis: The role of imagery ability. International Journal of Sport and Exercise Psychology, 5(2), 175-186. Retrieved from https://doi.org/10.1080/1612197X.2007.9671818

Rusdiana, A. (2020). Fatigue effect on movement kinematic changes of overhead jumping smash in badminton. Jurnal Sportif: Jurnal Penelitian Pembelajaran, 6(2), 272-287. Retrieved from https://doi.org/https://doi.org/10.29407/js_unpgri.vi.14101

Setyantoko, M., Widiastuti, W., \& Hernawan, H. (2019). The Game-Based ABC Running Exercise Model for Children Ages 6-12 Years. Budapest International Research and Critics in Linguistics and Education (BirLE) Journal, 2(3), 506-518. Retrieved from https://doi.org/10.33258/birle.v2i3.422

Sidik, D. Z. (2017). Mengajar dan Melatih Atletik (5th ed.). Bandung: Remaja Rodakarya.

Sobarna, A., Hambali, S., Sutiswo, S., \& Sunarsi, D. (2020). The influence learning used ABC run exercise on the sprint capabilities. Jurnal Konseling Dan Pendidikan, 8(2), 67. Retrieved from https://doi.org/10.29210/142100

Sugiyono. (2014). Metode Penelitian Pendidikan Pendekatan Kuantitatif, Kualitatif, dan R\&D. Bandung: Alfabeta.

Suharjana. (2013). Kebugaran Jasmani. Yogyakarta: Jogja Global Media.

Sukadiyanto, \& Muluk, D. (2011). Pengantar Teori dan Metodologi Melatih Fisik. Bandung: Lubuk Agung. 
Susiono, R., \& Hernawan. (2020). Analisis unifikasi pada gerak dasar running ABC mahasiswa FIO 2018 Universitas Negeri Jakarta. Gladi : Jurnal Ilmu Keolahragaan, 10(02), 112-120. Retrieved from https://doi.org/10.21009/GJIK.102.05

Tønnessen, E., Shalfawi, S. A., Haugen, T., \& Enoksen, E. (2011). The Effect of 40-m Repeated Sprint Training on Maximum Sprinting Speed, Repeated Sprint Speed Endurance, Vertical Jump, and Aerobic Capacity in Young Elite Male Soccer Players. Journal of Strength and Conditioning Research, 25(9), 2364-2370. Retrieved from https://doi.org/10.1519/JSC.0b013e3182023a65

Triansyah, A. (2020). Atletik 'Event Track'. Pontianak: PT. Putra Pabayo Perkasa.

Triansyah, A., \& Haetami, M. (2020). Efektivitas stretching, passive activity dan V02max dalam mencegah terjadinya delayed onset muscle soreness. Jurnal Keolahragaan, 8(1). Retrieved from https://doi.org/10.21831/jk.v8i1.29487

Wulandari, Y. A., \& Jannah, M. (2018). Pengaruh PETTLEP Imagery Terhadap Efikasi Diri Atlet Lari 100 Meter Perorangan The. Jurnal Psikologi Teori Dan Terapan, 8(2), 154-164. 